\title{
O ESTÁGIO CURRICULAR COMO ESPAÇO DE FORMAÇÃO E EXERCÍCIO DA DOCÊNCIA: REFLEXÕES SOBRE A PRÁTICA
}

\author{
Cléia Demétrio Pereira ${ }^{1}$ \\ Tânia Regina Unglaub²
}

\section{INTRODUÇÃO}

O estágio é uma prática acadêmica que permite ao estudante do curso de formação de professor vivenciar a pratica pedagógica entrelaçando os conhecimentos teóricos com a atuação docente. Ou seja, é um espaço de formação e exercício da docência. Com esta compreensão, o presente texto apresenta algumas reflexões sobre o Estágio Curricular Supervisionado na formação do professor, a partir do exercício docente realizados nos campos de estágios da educação básica. O objetivo é discutir e refletir sobre o estágio curricular como espaço de formação e exercício da docência, como experiências práticas, de acadêmicos egressos do curso de Pedagogia a Distância, do Centro de Educação a Distância da Universidade do Estado de Santa Catarina (CEAD/UDESC).

O curso de Pedagogia a Distância tem formado professores para atuar na educação básica desde o ano de 2003. Entre os anos de 2003 a 2011 graduaram-se 14.200 professores. No ano de 2011 iniciou uma outra etapa do curso, mediante convênio com a Universidade Aberta do Brasil (UAB). Um novo projeto político pedagógico foi elaborado e 32 municípios de Santa Catarina tiveram a presença de um Polo de Apoio equipados para realização e transmissão de webconferências, vídeo-aulas e encontros presencias conforme a proposta do curso. No ano de 2015 e início de 2016 graduaram-se 920 alunos. Este trabalho é resultado de estudos e reflexões dos acadêmicos que graduaram-se nos anos de 2015 e 2016.

Importa mencionar que, para o desenvolvimento do estágio curricular supervisionado, os educandos contaram com as orientações de uma docência

\footnotetext{
1 Professora da Universidade do Estado de Santa Catarina/Centro de Educação a Distância, Coordenadora de Estágio do Curso de Pedagogia a Distância do CEAD/UDESC. Contato: cleia.pereira@udesc.br

${ }^{2}$ Professora da Universidade do Estado de Santa Catarina. Centro de Ensino a Distância (CEAD/UDESC). Coordenadora de Estágio de Centro do CEAD/UDESC. Atua no Mestrado Profissional de Gestão de Unidades de Informação (PPGINFO). Contato: tania.unglaub@udesc.br
} 
compartilhada, entre professor da disciplina, professor tutor online, professor supervisor de campo e profissional referência da escola em que o estágio é desenvolvido.

Mas, até que ponto o Estágio Curricular Supervisionado pode tornar-se um espaço de formação e exercício da docência? Quando e como se aprende a ser professor, professora? Como articular a teoria com a prática? O Estágio Curricular Supervisionado contribui para que os saberes didáticos e pedagógicos, habilidades e competências para o exercício da docência sejam construídos?

Ser, e tornar-se professor não é tarefa tão fácil, considerando as rápidas transformações tecnológicas e científicas que refletem diretamente na formação das pessoas, em especial na formação de futuros professores. Para compreender melhor essa relação, buscamos as contribuições de Perez (2009), Nóvoa (1992), Alarcão (1996), Schön (1997), Pimenta e Lima (2004, 2006), Thiollent (2009), Pimenta (2010) e Ghedin (2008), dentre outros.

\section{QUADRO TEÓRICO - ESTÁGIO CURRICULAR COMO ESPAÇO DE FORMAÇÃO DOCENTE}

Partimos da premissa que o Estágio Curricular Supervisionado permite ao futuro professor conhecer e viver, na prática, experiências articuladas aos referenciais teóricos. Para subsidiar o exercício profissional do doente em formação, o estagiário necessita oportunizar o educando a possibilidade de apropriar-se dos saberes escolarizados em diferentes áreas, com base na interação entre a pesquisa e a prática pedagógica

Ghedin et al. (2015) salientam a importância de as universidades compreenderem a formação docente numa epistemologia da prática, subsidiada pelo conhecimento prático articulado com a pesquisa. O Estágio Curricular Supervisionado do curso de Pedagogia a Distância do CEAD/UDESC, tem este princípio educativo, pois propõe uma intervenção nos campos de estágio a partir de um processo investigativo. Na perspectiva de Ghedin (2015) o estágio curricular supervisionado possibilita uma educação científica, uma vez que,

[...] mediado pela pesquisa, o professor passa a ser sujeito do seu próprio conhecimento, ao problematizar e registrar as suas experiências pedagógicas, estará iniciando a construção de sua identidade docente, 
despertando também o sentimento de tornar-se professor-pesquisador. (GHEDIN et al., 2015, p. 99).

Importa registrar que o estágio passa pela "intervenção no campo educacional" e concebe a atividade de estágio como práxis educacional, primando pela unidade teoria e prática, que se efetiva pela pesquisa; logo emerge uma dimensão político-educacional de todo processo: a intervenção.

A intervenção no campo educacional do curso de Pedagogia a Distância Cead/Udesc é resultado de pesquisa em todo o processo. O exercício de formação docente no campo de estágio, inicia com a sondagem do campo de estágio por meio da leitura crítica de contexto do cenário educacional, observação direta, observação participante, diálogo com os educadores do campo de estágio análise documental, subsidiado em estudos teórico científicos. Essas etapas iniciais são técnicas de pesquisa o (a) estagiário(a) que permite a coleta de dados que subsidia a organização do Projeto de Pesquisa e possibilita a construção do Projeto de Intervenção Docente. Tanto o projeto de pesquisa como de intervenção apresentam temática(s) definida(s) com base na leitura crítica de contexto.

De acordo com Ghedin et al. (2015, p. 100), "[...] é possível o professor agir como pesquisador no contexto da escola" considerando que ele mesmo desenvolva "[...] uma visão crítica sobre o contexto em que está inserido questionando a sociedade, a escola, o ensino, porém ao mesmo tempo oferecendo sugestões, ou pelo menos abrindo espaços para discussão no ambiente escolar". Compreende-se, assim, que além de conhecer, é preciso também reconstruir a realidade; o conhecimento pressupõe a intervenção e a transformação escolar.

Esse cenário avança para o que se define como terceiro ato, "a transformação da realidade educacional", considerando que as ações de prática pedagógica e prática docente desenvolvidas durante os percursos dos estágios possam superar a "imitação de modelos ou a instrumentalização técnica" (PIMENTA; LIMA, 2005-2006, p. 4) para uma dimensão transformadora da práxis educacional, como forma de garantir a unidade dialética existente entre teoria e prática.

Ao encarar a ação educativa (práxis educacional) como uma prática social, admite-se a intenção de intervir na realidade social a partir da educação, transformando-a. Ao educar, promove-se a formação humana, por isso esse ato não pode ser ingênuo ou desprovido de intenção; pelo contrário, toda proposta educativa 
quer formar um determinado tipo de sujeito social, porque tem em vista uma visão de sociedade e de mundo, que baliza os modos de se fazer educação. E, quando a intenção passa pela intervenção no campo educacional, é preciso definir uma metodologia de pesquisa que tenha como princípio a interação do pesquisador com o campo pesquisado, que possa colaborar no processo de intervenção e também de transformação da realidade investigada.

Portanto, esse tipo de pesquisa, se configura no tipo "pesquisa-ação". Esta metodologia está em consonância com as especificidades requeridas no desenvolvimento da atividade de pesquisa, promovida pela disciplina de Estágio Curricular Supervisionado do curso de Pedagogia a Distância do CEAD/UDESC.

Pimenta (2006) destaca que a pesquisa no estágio permite a ampliação e análise dos contextos educativos, possibilitando o desenvolvimento de postura e habilidades de pesquisador a partir de situações de estágio. Também menciona que a elaboração de projetos de intervenção pedagógica lhes permite compreender, problematizar situações observadas e buscar soluções para o cotidiano escolar, à luz da teoria e da própria prática como lócus de pesquisa.

A sugestiva direção da pesquisa-ação como caminho metodológico do curso de Pedagogia a distância Cead/Udesc, dá-se pela compreensão de que esta estratégia de pesquisa é

[...] concebida e realizada em estreita associação com uma ação ou com a resolução de um problema coletivo e na qual os pesquisadores e os participantes representativos da situação ou do problema estão envolvidos de modo cooperativo ou participativo. (THIOLLENT, 2009, p. 16).

A pesquisa-ação caracteriza-se como método intervencionista ao permitir que o pesquisador teste suas hipóteses sobre o fenômeno em estudo, com a finalidade de provocar mudanças no cenário real, em busca de solução para o problema em questão, conforme os objetivos propostos.

A opção pela pesquisa-ação na formação acadêmica de professores no curso de Pedagogia a distância leva em consideração sua abordagem qualitativa e as possibilidades de envolvimento dos professores e demais profissionais ligados ao processo educativo no contexto escolar. Thiollent (2011, p. 32) salienta que a pesquisa-ação se caracteriza como "uma estratégia de pesquisa que agrega vários métodos ou técnicas de pesquisa social, com os quais se estabelece uma estrutura 
coletiva, participativa e ativa ao nível de captação de informações". Para este autor, este tipo de pesquisa caracteriza-se por intervir diretamente no contexto, com ações que podem inclusive provocar reflexões e até mesmo mudanças neste espaço, como forma de superar situações problemáticas em questão, denominada como fase intervencionista.

Com base nesse caminho metodológico, o professor-pesquisador tem a oportunidade de organizar sua pesquisa a partir dos conhecimentos práticos e científicos que direcionarão o próprio percurso de pesquisa, no âmbito escolar, inclusive, com a possibilidade de contribuir para a transformação dessa realidade. Assim como, também, de se manter vigilante na reflexão crítica sobre a prática educativa para gerar novos conhecimentos, em busca da transformação da sociedade, como destaca Freire (2006).

É nessa direção, que a formação inicial proporciona experiências em atividades de pesquisa e intervenção, como prática reflexiva, legitimada pelo estágio curricular do curso de Pedagogia, nesse caso especifico, além de outras possibilidades durante a própria formação acadêmica. Para Paulo Freire, o processo de ensino-aprendizagem e pesquisa são indissociáveis, pois é impossível haver ensino sem pesquisa e pesquisa sem ensino, considerando que essa relação se encontra num movimento único, fazendo parte do mesmo processo. "Não há ensino sem pesquisa e pesquisa sem ensino" (FREIRE, 2009, p. 32).

O estágio curricular na formação de professores possibilita os acadêmicos e futuros professores realizar pesquisas, analisá-las, inclusive, intervir no campos em que está inserido, como forma de contribuir para minimizar as situações problemas, ou quem sabe até, de superá-las. Compreendemos que é no espaço do contexto escolar, em seus diferentes níveis de formação, é que são identificadas as necessidades do contexto, das práticas e dos alunos, assim como também são analisadas as expectativas dos professores.

É nesse cotidiano que surgem as questões que alimentam a pesquisa, a fim de responder àquela realidade, na busca uma possível solução. Com base nas questões levantadas durante a pesquisa pudemos verificar que grande parte dos pedagogos que participaram de nossa pesquisa, entendem que o estágio curricular tenha sido o carro chefe da própria formação docente, relatado principalmente por aqueles que nunca tiveram um contato mais próximo com os campos de estágios. 
Entretanto, de acordo com alguns pedagogos que já atuavam na educação básica, mesmo assim, o período do estágio curricular, foi momento fundamental para se perceberem com um pesquisador dentro do próprio contexto, assim como de outros contextos, os quais realizaram seus estágios. Isabel Alarcão (2005) nos ajuda entender que formação de um professor, passa inevitavelmente pela ação de um pesquisador, que desenvolve uma investigação em íntima relação com a sua função de ser professor. Mediante as complexidades que envolvem a atuação do professor, passa, decisivamente, pela oportunidade de se constituir professor no campos de estágio, como também de um professor pesquisador da sua própria prática pedagógica, a partir de um olhar crítico e reflexivo, como destacam Pimenta (2010) e Ghedim (2008).

Nessa discussão, é de se considerar que o professor reflexivo/pesquisador pode produzir conhecimento a partir de sua própria prática, mas que essa possibilidade de investigação reflita intencionalmente sobre ela, no exercício da docência e de suas relações com a própria formação profissional e da transformação social.

Desse modo, é fundamental que o futuro professor, durante sua formação inicial se aproprie de conhecimentos fundamentais, "capazes de torná-los criadores de estratégias e métodos de intervenção, cooperação, análise, reflexão e a construir um estilo rigoroso e investigativo", características inerentes de um professor pesquisador e reflexivo, como destaca Perez (2009, p. 271).

\section{METODOLOGIA}

Para levantar informações que contribuísse para nossas análises, contamos com a participação de egressos do curso de Pedagogia da UDESC/CEAD, de diferentes polos distribuídos pelo estado de Santa Catarina. Portanto, de acordo com os objetivos propostos trata-se de uma pesquisa tipo estudo de caso, onde os dados são analisados na perspectiva da abordagem metodológica qualitativa.

De acordo com Martins e Theóphilo (2009), complementam que esse método de pesquisa exige uma avaliação qualitativa profunda e intensa de um núcleo social. Nas palavras dos autores, esse tipo de pesquisa caracteriza-se por ser "[...] uma investigação empírica que pesquisa fenômenos dentro de seu contexto 
real (pesquisa naturalística) [...], buscando apreender a totalidade de uma situação e, criativamente, descrever, compreender e interpretar a complexidade de um caso concreto" (MARTINS; THEÓPHILO, 2009, p. 62).

A pesquisa estudo de caso possibilita a coleta de dados por meio de vários instrumentos entre os quais estão as entrevistas abertas ou fechadas, exame documental, observação participante, direta ou indireta entre outras. Para a realização da coleta de dados, ocorreram entrevistas semiestruturadas aplicadas na forma de questionários online, com perguntas fechadas e algumas com questões abertas, com o intuito de capitar percepções de professores já formados. Também foram examinados documentos que contem reflexões críticas de egressos sobre a disciplina de estágio. Esses documentos são: alguns relatórios finais de estágio e avaliações dos alunos referente a disciplina de estágio disponível no fórum de discussão no Ava-moodle.

A seleção dos egressos deu-se levando em conta as diferentes regiões de Santa Catarina, formados no período compreendido entre 2015 e 2016, anos que ocorreram a formatura das primeiras turmas do curso de Pedagogia, ofertada na modalidade a distância, pelo CEAD/UDESC.

\section{RESULTADOS E DISCUSSÃO}

O estágio curricular na formação de professores possibilitou os acadêmicos e futuros professores realizar pesquisas, analisá-las, inclusive, intervir no campos em que está inserido, como forma de contribuir para minimizar as situações problemas, ou quem sabe até, de superá-las. Verificou-se que grande parte dos pedagogos que participaram da pesquisa, entenderam que o estágio curricular foi o carro chefe da própria formação docente.

De acordo com o depoimento de um participante, regsitrado no fórum de avaliação no ambiente virtual da disciplina, o "estágio curricular supervisionado é uma prática acadêmica que permite ao estudante de nível superior experimentar na prática os conhecimentos teóricos aos quais tem acesso durante o curso". (Participante 1) Também destacam a importância das orientações dos futuros professores para se tornarem pesquisadores, pois, 
A academia orienta através da oferta de conhecimento teórico, a formação de profissionais que entendam o que é ser professor, que no conceito de hoje, não é mais o transmissor do conhecimento, mas o mediador, o pesquisador de sua própria prática. A prática de estágio não equilibra teoria e prática, mas é um momento oportuno para que o acadêmico, enquanto pesquisador, vá a campo perceber a realidade na qual poderá atuar, para, exatamente, articular os conceitos teóricos com esse espaço e com esse público. (...). Por isso nem a prática de estágio nem o curso de pedagogia torna alguém educador, mas ensina a observar e pesquisar. (Participante 2).

Sobre a importância da orientação da formação do professor como pesquisador também é percebida em alguns pedagogos que já atuavam na educação básica. Para eles, o período do estágio curricular foi momento fundamental para se perceberem com um pesquisador dentro do próprio contexto, assim como de outros contextos, os quais realizaram seus estágios.

Isabel Alarcão (2005) nos ajuda entender que formação de um professor, passa inevitavelmente pela ação de um pesquisador, que desenvolve uma investigação em íntima relação com a sua função de ser professor.

\section{CONCLUSÃO}

A formação do professor envolve diretamente o contato com a realidade escolar, por meio do estágio curricular, durante a sua formação acadêmica. Esse processo passa, decisivamente, pela oportunidade de se constituir professor como pesquisador e reflexivo de sua própria prática pedagógica, (PIMENTA; GHEDIM (2008).

Para Tardif (2007, p. 288) "a formação inicial visa a habituar os alunos os futuros professores - à prática profissional dos professores de profissão e a fazer deles professores "reflexivos"”.

Por fim, as percepções dos egressos do curso de Pedagogia da UDESC, apontam o estágio curricular como um eixo determinante na formação do professor, bem como na transformação da realidade e da construção da própria identidade de ser professor.

\section{REFERÊNCIAS}


ALARCÃO, Isabel. Professores reflexivos em uma escola reflexiva. 4. ed. São Paulo, Cortez, 2005.

FREIRE, Paulo. Pedagogia da Autonomia. 43 ed. São Paulo: Paz e Terra, 2009.

GHEDIN, Evandro. et al. Estágio com pesquisa. São Paulo: Cortez, 2015.

MARTINS, Gilberto de Andrade; THEÓPHILO, Carlos Renato. Metodologia da investigação científica para ciências sociais aplicadas. 2. ed. São Paulo, SP: Atlas, 2009.

PEREZ, Geraldo. Formação de Professores de Matemática sob a Perspectiva do Desenvolvimento Profissional. In: Pesquisa em Educação Matemática: Concepções e Perspectivas. Bicudo, M. A. V. (org.). São Paulo, Unesp, Cap. 15, 1999, p. 263-282.

PIMENTA, Selma Garrido. O Estágio na Formação de Professores: unidade teoria e prática. São Paulo: Cortez, 2005.

PIMENTA, Selma Garrido; GHEDIM, Evandro. Professor Reflexivo no Brasil: gênese e crítica de um conceito. São Paulo: Cortez, 2008.

PIMENTA, Selma Garrido; LIMA, Maria S. Lucena. Estágio e docência: diferentes concepções. Revista Poiésis. v.3, n.3, 2005/2006.

SCHÖN, Donald. Formar professores como profissionais reflexivos. In: NÓVOA, A. Os Professores e a sua formação. Lisboa: Dom Quixote, 1997.

TARDIF, Maurice. Saberes docentes e formação profissional. $4^{a}$ Ed. Rio de Janeiro: Vozes, 2002.

THIOLLENT, Michel. Metodologia da pesquisa-Ação. 18. ed. São Paulo: Cortez, 2009. 